\title{
Ceratoconjuntivite alérgica e complicações no seg̉mento ocular anterior de pacientes
}

\author{
Evaluation of anterior ocular segment complications in patients with allergic \\ keratoconjunctivitis
}

\author{
Patrícia Bezerra de Menezes Botelho ${ }^{1}$ \\ Patrícia Marback ${ }^{2}$ \\ Luciene Barbosa de Sousa ${ }^{2}$ \\ Mauro Campos ${ }^{3}$ \\ Luiz Antonio Vieira ${ }^{4}$
}

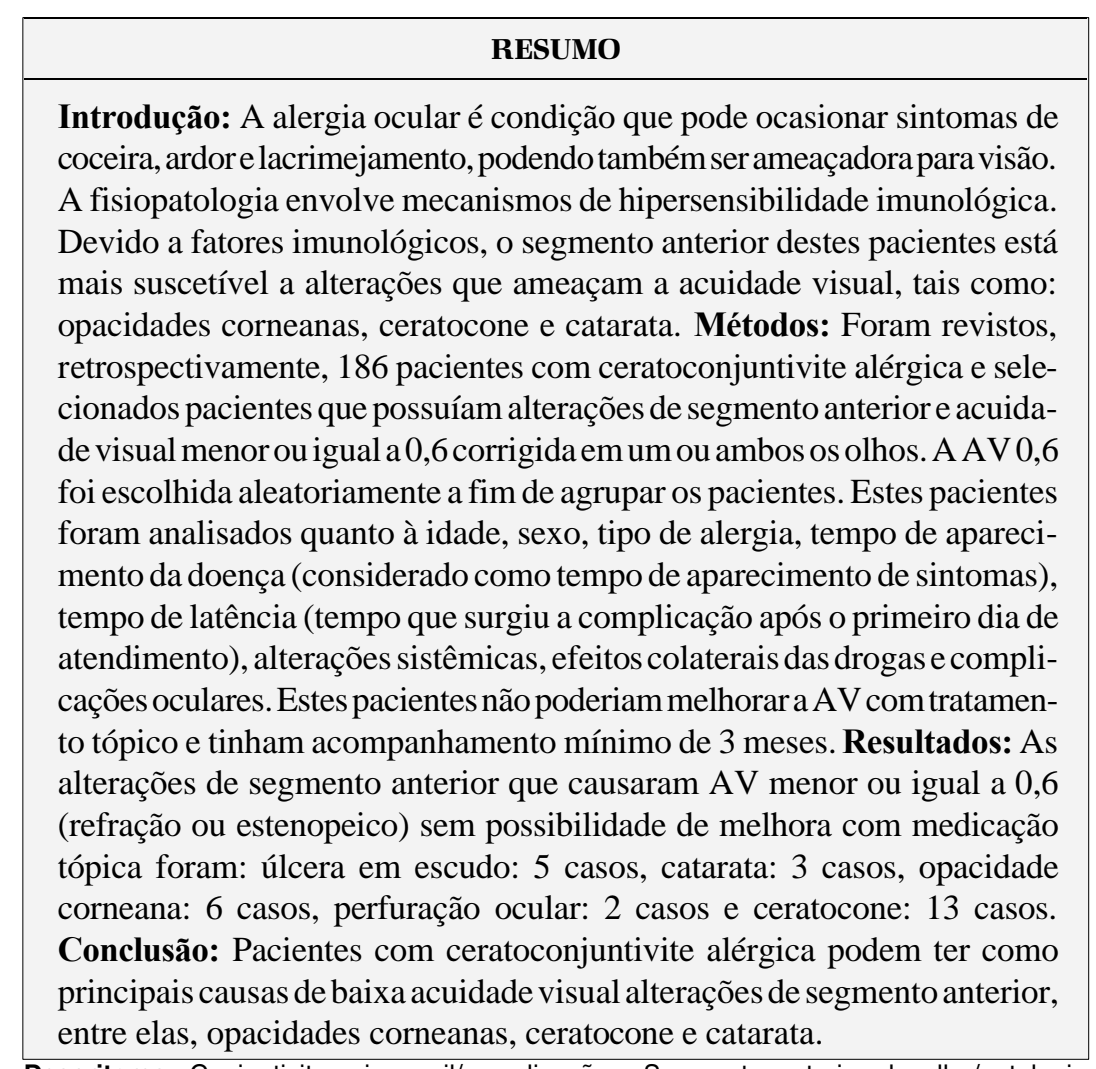

Oftalmologista especialista em córnea pela Universidade Federal de São Paulo - UNIFESP.

${ }^{2}$ Doutora em Oftalmologia pela Universidade Federal de São Paulo - UNIFESP.

${ }^{3}$ Professor livre-docente pela Universidade Federal de São Paulo - UNIFESP.

${ }^{4}$ Doutor em Oftalmologia pela Universidade Federal de São Paulo - UNIFEP.

Endereço para correspondência: Rua Esmeralda Gomes Vieira, 42 - João Pessoa (PB) CEP 58051-650.

E-mail: patymenezes@oftalmo.epm.br

Recebido para publicação em 03.04.2001

Aceito para publicação em 12.06.2002

Nota Editorial: Pela análise deste trabalho e por sua anuência sobre a divulgação desta nota, agradecemos aos Drs. João Luiz Lobo Ferreira e Carlos Augusto Moreira.
Descritores: Conjuntivite primaveril/complicações; Segmento anterior do olho/patologia

\section{INTRODUÇÃO}

Introdução: A alergia ocular é condição que pode ocasionar sintomas de A fisiopatologia envolve mecanismos de hipersensibilidade imunológica. Devido a fatores imunológicos, o segmento anterior destes pacientes está mais suscetível a alterações que ameaçam a acuidade visual, tais como retrospectivamente, 186 pacientes com ceratoconjuntivite alérgica e selecionados pacientes que possuíam alterações de segmento anterior e acuidade visual menor ou igual a 0,6 corrigida em um ou ambos os olhos. A AV 0,6 foi escolhida aleatoriamente a fim de agrupar os pacientes. Estes pacientes foram analisados quanto à idade, sexo, tipo de alergia, tempo de aparecitempo de latência (tempo que surgiu a complicação após o primeiro dia de atendimento), alterações sistêmicas, efeitos colaterais das drogas e complito tópico e tinham acompanhamento mínimo de 3 meses. Resultados: As alterações de segmento anterior que causaram AV menor ou igual a 0,6 (refração ou estenopeico) sem possibilidade de melhora com medicação corneana: 6 casos, perfuração ocular: 2 casos e ceratocone: 13 casos. Conclusão: Pacientes com ceratoconjuntivite alérgica podem ter como entre elas, opacidades corneanas, ceratocone e catarata.

\begin{abstract}
Descritores: Conjuntivie primaverilcomplcaços: Segmento anterior do olho/patologia
\end{abstract}
A alergia ocular pode ser doença simples com sintomas de coceira, ardor e lacrimejamento, porém pode ser ameaçadora para a visão. Geralmente está envolvido um processo de hipersensibilidade do tipo $\mathrm{I}^{(1)}$.

A fisiopatologia da doença ocular crônica envolve atividade de eosinófilos e produção de citoquinas. Há 2 etapas principais no mecanismo imunológico.

A primeira envolve atividade das células de Langerhans, as quais apresentam o antígeno que interage com linfócito $\mathrm{T}$ helper. As interleucinas (IL), liberadas por este, estimulam o linfócito B que sofrerá um desvio na produção de IgG para a produção de IgE.

$\mathrm{Na}$ outra etapa a IgE entra em contato com os anticorpos das membranas dos mastócitos, e, assim, ocorre o processo de degranulação de mastócitos. Ocorre então, liberação de mediadores vasoativos, enzimas e 
mediadores químicos, tais como fator quimiotáxico eosinofílico ${ }^{(1)}$.

O tratamento depende da condição clínica do paciente e envolve orientação quanto ao afastamento dos agentes de sencadeantes da alergia, além do uso de anti-histamínicos, estabilizadores de mastócitos, anti-inflamatórios hormonais e compressas geladas ${ }^{(2)}$.

Doenças corneanas consideradas de alta morbidade, tais como neovascularização, ceratopatia lipídica, defeitos epiteliais persistentes e ceratites supurativas são comuns em pacientes com ceratoconjuntivite alérgica ${ }^{(3)}$.

O equilíbrio entre a medicação ideal e os efeitos colaterais das drogas como glaucoma, infecções e catarata são o objetivo do acompanhamento ${ }^{(2)}$.

Este trabalho tem como objetivo apontar complicações que causaram baixa acuidade visual em pacientes alérgicos crônicos em um serviço de referência terciária na cidade de São Paulo.

\section{MÉTODOS}

Analisados, retrospectivamente, pacientes com conjuntivite alérgica atendidos no ambulatório de patologia externa do hospital São Paulo de 1997 a 2000. Foram avaliados quanto à acuidade visual e complicação ocular e selecionados casos em que a causa de baixa acuidade visual foi alteração de segmento anterior do globo ocular, tais como ceratocone, úlcera escudo, opacidades de córnea com neovascularização, catarata e perfuração ocular.

Foram considerados casos de alta morbidade, casos em que havia AV(acuidade visual) corrigida, ou com auxílio de buraco estenopeico menor ou igual a 0,6 (tabela de Snellen) em pelo menos um dos olhos, e que não tiveram melhora com tratamento clínico.

Nestes pacientes foram analisados sexo, idade, data do primeiro atendimento $(\mathrm{CN})$, tipo de conjuntivite (classificado de acordo com tempo da evolução e sintomas), tempo de apareci-

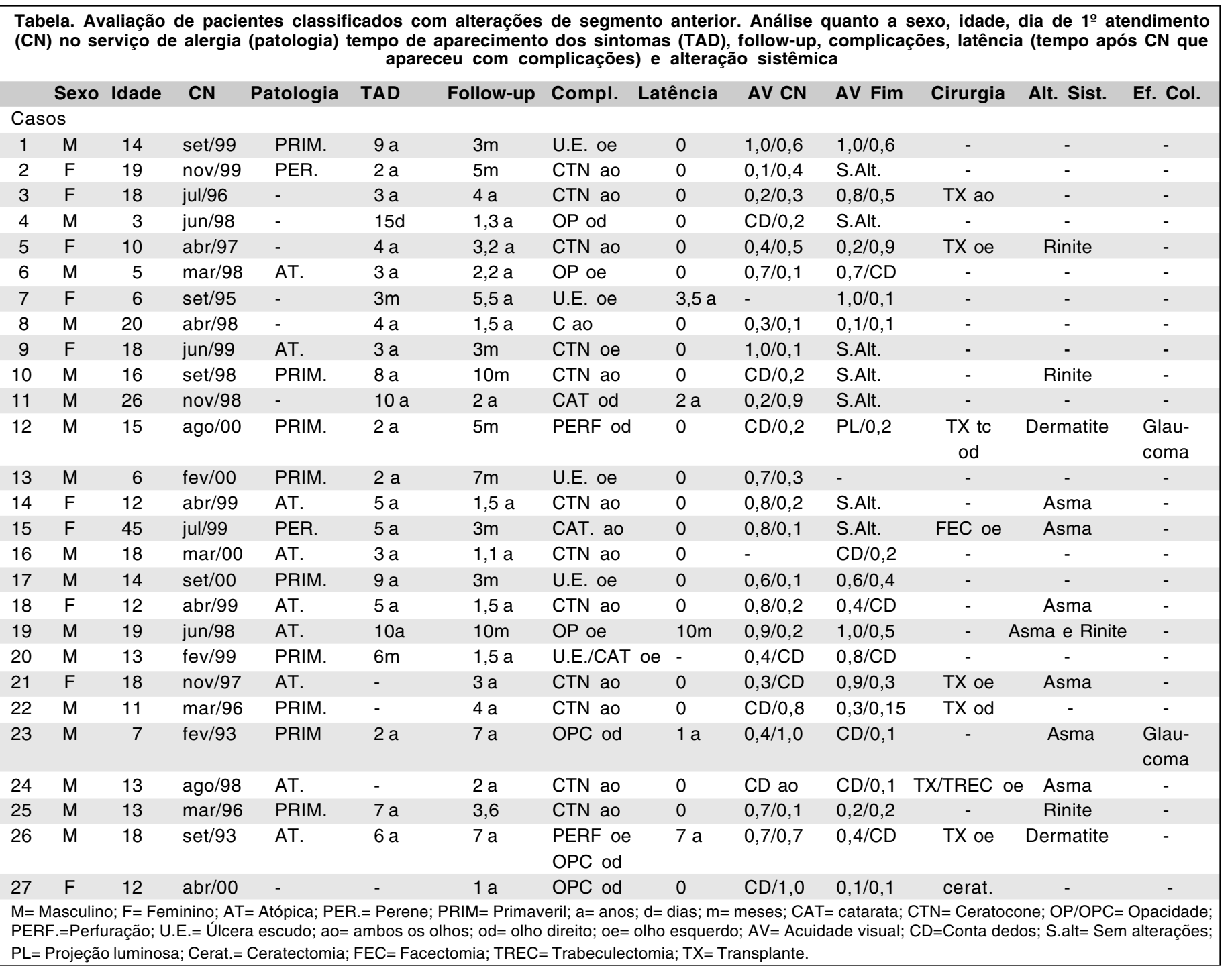


mento da doença (TAD), seguimento, complicações oculares, acuidade visual no primeiro dia e no último dia de seguimento, cirurgia realizada, medicação usada e efeito colaterais. Todos os pacientes deveriam ter "follow-up" mínimo de 3 meses.

\section{RESULTADOS}

Foram analisados os prontuários de 186 pacientes com conjuntivite alérgica, sendo que, destes, 57 (30,64\%) tinham diagnóstico de conjuntivite atópica, $5(2,6 \%)$ de conjuntivite perene, $78(41,9 \%)$ de conjuntivite primaveril e $26(13,97 \%)$ casos com diagnóstico de conjuntivite alérgica apenas, nos quais não foi caracterizado o diagnóstico diferencial. Selecionou-se 27 casos que foram considerados de alta morbidade.

Os resultados da avaliação dos 27 pacientes com alterações de segmento anterior e AV menor ou igual a 0,6 são apresentados nas tabelas anexas. A idade variou de 3 a 45 anos com a média de 13 anos. Dezessete pacientes eram do sexo masculino e 10 do sexo feminino. As alterações de alta morbidade (27 casos selecionados) de segmento anterior foram: úlcera em escudo(UE), 5 casos; catarata, 3 casos; opacidade corneana(OP), 6 casos; perfuração ocular, 2 casos; ceratocone, 13 casos. Houve 7 cirurgias, sendo 2 transplantes de córnea tectônicos, 4 transplantes de córnea ópticos e uma ceratectomia, cujo diagnóstico de biópsia foi hiperplasia epitelial, proveniente de um caso com opacidade e irregularidade de córnea (Figura 1).

O tempo de aparecimento de doença equivale ao tempo de aparecimento de sintomas, informando no primeiro dia de consulta e variou entre 15 dias e 10 anos. O seguimento variou de 3 meses a 7 anos. Comparando-se a AV inicial e final; 11 olhos $(20,75 \%)$ melhoraram a AV, 12 olhos $(22,6 \%)$ tiveram piora, 26 olhos (49\%)tiveram alterações e 4 olhos $(7,5 \%)$ não tiveram medida inicial. Sete olhos foram transplantados, havendo melhora de AV em 5 olhos e 2 olhos tiveram piora, porém foram transplantes tectônicos.

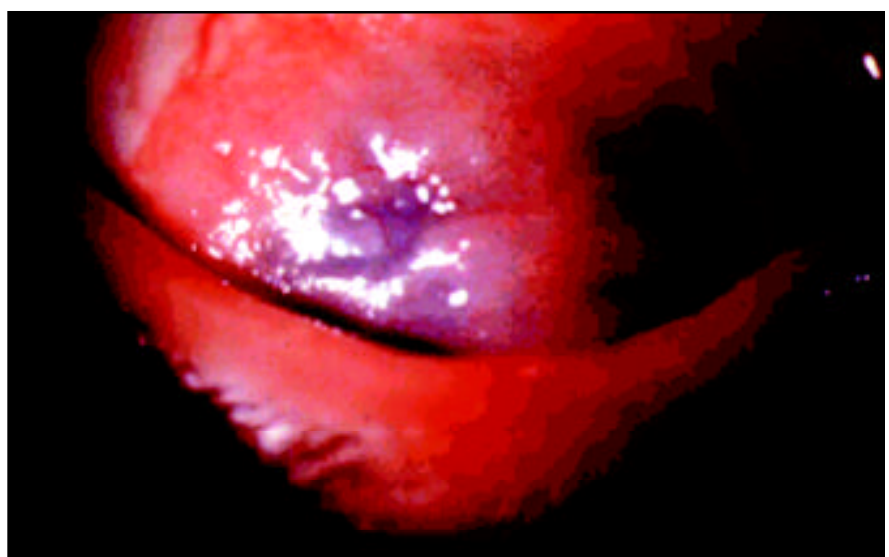

Figura 1 - Irregularidade epitelial (caso 27 da tabela)

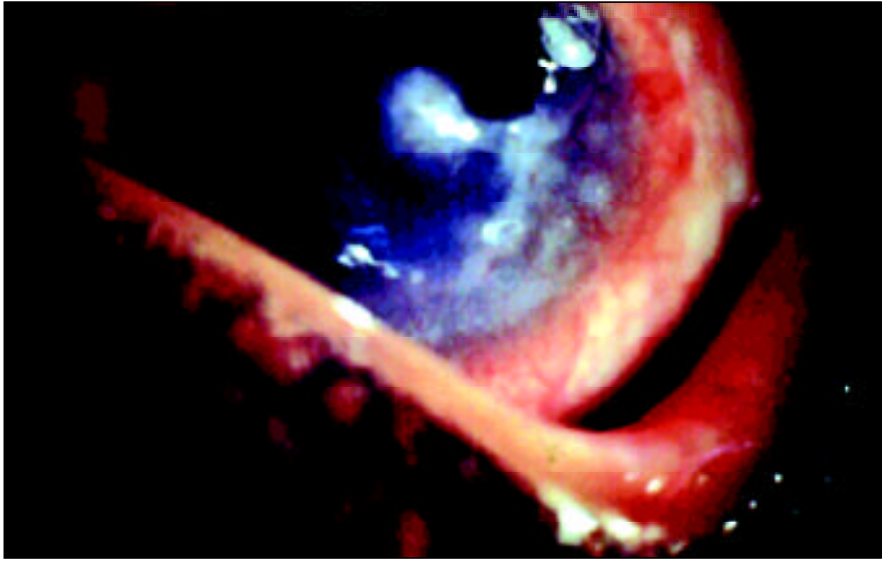

Figura 2 - Opacidade neovascular (caso 23 da tabela)

O tempo de aparecimento de sintomas dos pacientes com complicação ocular no primeiro dia variou de 2 a 9 anos. $\mathrm{O}$ tempo de seguimento dos pacientes acompanhados no ambulatório e com complicações presentes variou de 5 meses a 7 anos, o tempo de aparecimento de complicações oculares (latência) variou de 10 meses a 7 anos.

Um caso com catarata teve acompanhamento de 2 anos, porém no primeiro dia de atendimento em nosso serviço (HSP) tinha os sintomas há 10 anos, segundo prontuário.

Uma perfuração teve acompanhamento de 7 anos no HSP e ocorreu num paciente atópico, usuário crônico de corticóide tópico, que evoluiu previamente com ceratite herpética. Este apresentou, na cultura do botão receptor, crescimento de Staphylococcus aureus.

\section{DISCUSSÃO}

No processo fisiopatológico de ceratoconjuntivites alérgicas ocorre a liberação de mediadores vasoativos, enzimas e mediadores químicos, entre eles, o fator quimiotáxico eosinofílico e a proteína básica maior.

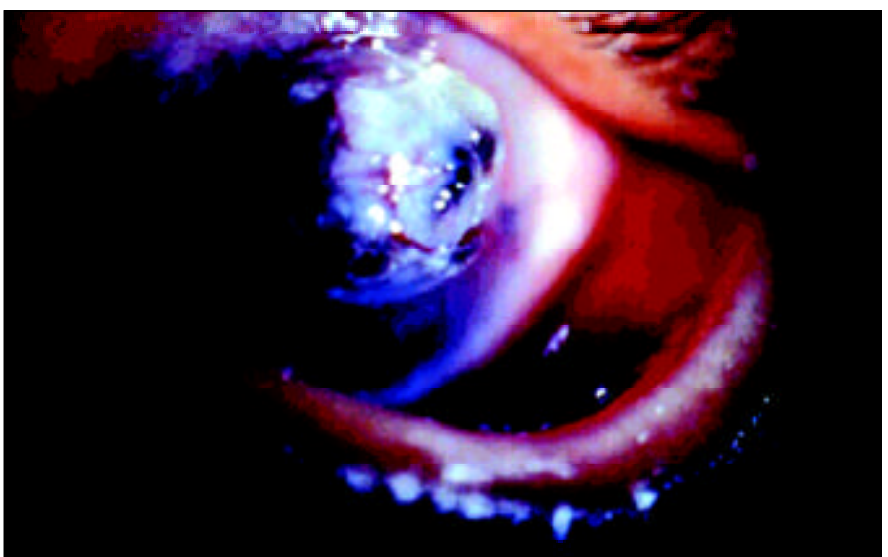

Figura 3 - Perfuração (caso 12 da tabela) 
Há outros mecanismos envolvidos na patogênese, além da hipersensibilidade tipo $\mathrm{I}^{(1)}$; alguns achados imunopatológicos são semelhantes aos achados de conjuntiva de pacientes com penfigóide cicatricial e rosácea. A ativação de fibroblastos, proliferação e produção de cicatriz podem resultar de variedade de doenças inflamatórias crônicas, em que a célula T, macrófagos e mastócitos interagem ${ }^{(4)}$.

Em conjuntiva de pacientes com ceratoconjuntivite vernal foram identificados a proteína básica maior (PBM) e o fator quimiotáxico eosinofílico (FQE); em experimentos em defeitos epiteliais. Além disto, foi demonstrado em vitro que a PBM e o FQE afetaram a viabilidade e a morfologia de células ${ }^{(5)}$.

O transplante nestes pacientes tem uma alta taxa de falência do botão, porém pode ser indicado quando a superfície ocular está bem controlada, obtendo-se melhora da acuidade visual ${ }^{(6)}$.

No estudo em questão, 20 pacientes se apresentaram com complicação ocular no primeiro dia de atendimento, o que está relacionado com encaminhamento tardio para o nosso serviço de referência terciária.

Na literatura há complicações citadas como causas de baixa acuidade visual como: catarata induzida por corticóide $(8 \%)$, cicatrizes corneana central $(7 \%)$ e glaucoma induzido por corticóide $(4 \%)^{(7)}$.

A porcentagem de pacientes com alergia ocular e ceratocone varia de 10 a $16 \%{ }^{(3-7)}$ Admite-se a possibilidade de causas genéticas ou adquiridas pela alergia. Poder-se-ia realizar trabalhos prospectivos e genéticos com melhores definições destas hipóteses.

O ceratocone foi o principal responsável pela baixa acuidade visual no grupo de pacientes selecionados (27 casos) com alterações de segmento anterior, apresentou-se em 50\% dos pacientes. Em dados ainda não divulgados o ceratocone no Hospital São Paulo esteve em 13,45\% dos pacientes com conjuntivite alérgica.

Setenta e cinco a $80 \%$ dos pacientes com conjuntivite primaveril podem ter outras manifestações ${ }^{(3)}$. Ocorreu alterações sistêmicas (rinite, dermatite, asma) em 12 pacientes.

Houve relato de pacientes com ceratoconjuntivite vernal em que a percentagem de AV corrigida pior que $20 / 200$ foi de $21 \%{ }^{(7)}$. No estudo em questão 12 pacientes dos 186 prontuários revistos tinham $\mathrm{AV} \leq 0,1$ no pior olho, cerca de $6,45 \%$ dos pacientes.

"Follow-up" de 3 anos realizado em 20 pacientes com conjun- tivite alérgica demonstrou $70 \%$ de ceratopatia significante (úlcera corneana, defeito epitelial persistente e neovascularização) $)^{(4)}$.

Os pacientes com ceratoconjuntivite alérgica são pacientes com risco maior de cegueira, devido a fatores complexos imunológicos que culminam com ceratites e outras complicações, tais como ceratocone, opacidade neovascular e catarata.

\section{ABSTRACT}

Purpose: To evaluate complications of allergic keratoconjuctivitis that caused reduction in visual acuity to 0.6 or less and that could not solve with clinic treatment. Methods: We analyzed retrospectively 186 charts and selected patients with visual acuity less than 0.6 on Snellen chart, associated with secondary anterior segment alterations. Data collected from the charts were: age, gender, kind of allergy, time of disease, time that complication appeared after treatment in our Service, side effects and ocular complications. Results: Complications of anterior segment that caused reduction in visual acuity were: shield ulcers, 5 cases; cataract, 3 cases; corneal opacity, 6 cases; ocular perforation, 2 cases and keratoconus 13 cases. There were 7 surgeries: 2 tectonic penetrating keratoplasty, 4 optic keratoplasty, 4 optic penetrating keratoplasty and one superficial keratectomy. Conclusion: Patients with allergic keratoconjunctivitis should be treated in order to prevent ocular complications like keratitis, keratoconus, opacities and cataract.

Keywords: Conjunctivitis, allergic/complications; anterior eye segment/pathology

\section{REFERÊNCIAS}

1. Àtean SJ, TimiAsoara. Corneal ulcerative lesion in the I immediate hypersensitivity. Oftalmologia 1998;44:3,20-6.

2. Holzchuh N, Kara-José N, Alves MR. Alergia. In: Kara-José N, Belfort Junior R. Córnea: clinica e cirúrgica. São Paulo:Roca;1997. p.251-62.

3. Tuft SJ, Kemeny DM, Dart JK, Buckley RJ. Clinical features of atopic keratoconjunctivitis. Ophthalmology 1991;98:150-8.

4. Power WJ, Tugal-Tutkun I, Foster CS. Long-term follow-up of patients with atopic keratoconjunctivitis. Ophthamology 1998;105:637-42

5. Trocmé SD, Hallberg CK, Gill KS, Gleich GJ, Tyring SR. Brysk MM. Effects of eosinophil granule proteins on human corneal epithelial cell viability and morphology. Invest Ophthalmol Vis Sci 1997;38:593-9.

6. Ghoraishi M, Akova YA, Tugal-Tutkun I, Foster CS. Penetrating keratoplasty in atopic keratoconjunctivitis. Cornea 1995;14:610-3.

7. Tabbara KF. Ocular complications of vernal keratocojuntivitis. Can J Ophthalmol 1999:34:88-92. 